\title{
Association of the proliferation of lung fibroblasts with the ERK1/2 signaling pathway in neonatal rats with hyperoxia-induced lung fibrosis
}

\author{
YU HU, JIANHUA FU and XINDONG XUE \\ Department of Pediatrics, Shengjing Hospital of China Medical University, Shenyang, Liaoning 110004, P.R. China
}

Received November 3, 2017; Accepted November 8, 2018

DOI: $10.3892 /$ etm.2018.6999

\begin{abstract}
Bronchopulmonary dysplasia (BPD) is a common, serious complication occurring in premature infants. Although clinical characteristics and pathologic changes are well described, the pathogenesis of alveolar dysplasia and interstitial fibrosis is less clear. Lung fibroblasts (LFs) are present in the extracellular matrix and serve essential roles during pulmonary epithelial injury and in response to fibrosis development in BPD. The current study investigated hyperoxia-induced proliferation of primary LFs in vitro and mechanisms that may be involved. Newborn rats were exposed to $90 \%$ oxygen, while control rats were kept in normal atmosphere. Primary LFs were isolated on postnatal day 3, 7 and 14. Hyperoxia-induced proliferation of LFs isolated on day 7 and 14 by accelerating the cell cycle progression from $\mathrm{G} 1$ to $\mathrm{S}$ phase. Collagen type I protein secretion and mRNA expression on day 7 and 14 were increased by hyperoxia compared with the controls. Hyperoxia significantly increased the phosphorylation of extracellular signal-regulated kinase (ERK) and significantly increased collagen type I expression compared with the room air control group. The findings indicated that an increase in LF proliferation in response to hyperoxia was associated with ERK1/2 phosphorylation. This mechanism may contribute to over-proliferation of LFs leading to disturbed formation of normal alveoli.
\end{abstract}

\section{Introduction}

Oxygen treatment is a life-saving therapy in infants with hypoxic respiratory failure (1). However, excessive oxygen

Correspondence to: Dr Xindong Xue, Department of Pediatrics, Shengjing Hospital of China Medical University, 36 Sanhao Street, Shenyang, Liaoning 110004, P.R. China

E-mail: xdxue1111@126.com

Abbreviations: ERK, extracellular signal-regulated kinase; BPD, bronchopulmonary dysplasia; Col-I, collagen type I; LFs, lung fibroblasts

Key words: hyperoxia, lung fibroblast, extracellular signal-regulated kinase, fibrosis exposure (hyperoxia) can interfere with the normal development by affecting cell division and differentiation in the immature lung (2). Hyperoxia can result in alveolar damage, pulmonary interstitial fibrosis and pulmonary vasculature dysplasia (3). Normal lung development depends on orderly proliferation of epithelial and mesenchymal cells, and interruption of that process impacts lung structure and function. Excessive oxygen exposure or hyperoxia may cause bronchopulmonary dysplasia (BPD) in the immature lung of premature neonates (4). BPD is the most common cause of respiratory morbidity among preterm infants, affecting nearly 10,000 infants each year in the United States (5). The pathological characteristics of BPD include simplified, enlarged alveoli, capillary deformation and interstitial fibrosis (6). Although much attention has been directed to lung epithelial and endothelial cells, pulmonary interstitial fibroblasts are also active during normal development and in response to hyperoxia (7). The development, repair and regeneration of alveoli are affected by neighboring lung fibroblasts (LFs), which further promote remodeling of the extracellular matrix (ECM) and development of fibrosis (8).

Lung development is controlled by spatial and temporal patterns of cell proliferation that are an important determinant of the lung architecture. Pulmonary epithelial and mesenchymal cells interact during localized growth, branching and extension of primordial tubules (9). Glandular and vascular development is associated with decreased proliferation of LFs (10). Disruption of the regulation of developmental patterns contributes to BPD, which often occurs in premature infants exposed to hyperoxia (5). BPD induces patchy proliferation of mesenchymal derivatives, including fibroblasts (8) and the regulation of LF proliferation is of clinical and developmental interest.

The extracellular signal-regulated kinase (ERK) cascade activates cell proliferation and experimental animal studies have demonstrated that the ERK1/2 signaling pathway can be activated by hyperoxia $(11,12)$. The Mek gene that encodes for ERKs is active in lung development and Mek mutations have been associated with lung hypoplasia, tracheal defects and neonatal deaths (13). LFs function as secretory cells in the pulmonary ECM and mediate normal and pathological remodeling. This study investigated cell proliferation and the activation of the ERK1/2 signaling pathway in primary cultures of LFs in a neonatal rat model of hyperoxia-induced lung fibrosis. 


\section{Materials and methods}

Animals and oxygen exposure. In the hyperoxia group, full-term newborn Wistar rats $(\mathrm{n}=60,3.7-4.2 \mathrm{~g})$ and 3-month old mother rats $(\mathrm{n}=40,220-240 \mathrm{~g})$ were provided by the Department of Laboratory Animals, Shengjing Hospital of China Medical University (Shenyang, China). Rats were exposed to an atmosphere of $90 \%$ oxygen with $\mathrm{CO}_{2}$ maintained at $<5 \%$ using soda lime. The temperature was kept at $25-27^{\circ} \mathrm{C}$ and the humidity at $50-70 \%$. In the control group full-term newborn Wistar rats $(n=60)$ were kept in room air (normoxia, $21 \%$ oxygen). To avoid oxygen toxicity, nursing mothers were rotated every $24 \mathrm{~h}$ between the groups. All rats had free access to food and water and were kept on a 12-h light/dark cycle. The current study was approved by the Institutional Animal Care and Use Committee at Shengjing Hospital of China Medical University (Shenyang, China). Newborn rats were euthanized prior to the removal of lung tissue with sodium pentobarbital $(100 \mathrm{mg} / \mathrm{kg}$ body weight; intraperitoneal injection). Lung tissue samples were collected on day 3 for saccular, day 7 for early alveolar or day 14 for bulk alveolar stages ( $\mathrm{n}=20$ each).

Lung histology and immunohistochemistry. Lung tissue samples were washed with PBS and fixed in $4 \%$ paraformaldehyde overnight at $4^{\circ} \mathrm{C}$ prior to dehydration in a graded alcohol series (80,90, 95 and 100\%) for $2 \mathrm{~h}$ at room temperature and embedded in paraffin. Paraffin-embedded lung tissue samples were cut into 4- $\mu \mathrm{m}$ slices and hematoxylin and eosin (H\&E) staining was performed. Briefly, samples were stained with haematoxylin for $10 \mathrm{~min}$ at room temperature, followed by eosin for $20 \mathrm{sec}$ at room temperature and standard histological evaluation was observed using a light microscope (magnification, $\mathrm{x} 400$ ).

The alveolar developmental stage was determined by a radial alveolar count (RAC), as previously described (14). A perpendicular line was drawn from the center of the most peripheral bronchiole to the pleura or the nearest interlobular septum. Alveolarization was evaluated by counting the number of alveoli crossed by this line.

Fibrosis was scored as previously described by Ashcroft et al (15). Each successive field was individually assessed for severity of interstitial fibrosis and given a score between 0 and 8 . Normal tissue received a score of 0 , whilst a high score of 8 was given to fields that were completely filled with fibrous tissue.

The immunohistochemical peroxidase-conjugated streptavidin method was performed to detect the expression level of phosphorylated (p)-ERK expression using an Histostain ${ }^{\mathrm{TM}}$-Plus kit (cat. no. SP-0023; OriGene Technologies, Inc., Beijing, China), according to the manufacturer's protocol. Briefly, paraffin-embedded lung tissue samples were blocked for $20 \mathrm{~min}$ at room temperature with $10 \%$ goat serum and incubated with the primary antibody against p-ERK (1:100; cat. no. 4370; Cell Signaling Technology, Inc., Danvers, MA, USA) overnight at $4^{\circ} \mathrm{C}$. Following incubation, tissue samples were incubated with biotinylated secondary antibody for $20 \mathrm{~min}$ at room temperature followed by horseradish peroxidase (HRP)-labeled streptavidin for $20 \mathrm{~min}$ at room temperature. The tissue sample slides were incubated with diaminobenzidine (DAB) solution (20X; cat. no. ZLI-9031; OriGene Technologies, Inc.) for color development and observed using a light microscope (magnification, $\mathrm{x} 400$ ). Tissue samples were subjected to morphometric computerized image analysis using MetaMorph Software System (IPv6.0; Universal Imaging, Inc., Bedford Hills, NY, USA), which was used to acquire images and quantify the number of positively stained cells. DAB precipitates as a dark brown pigment allowing easy visualization of positively stained cells. For each slide, five high magnification (x400) fields in total were randomly examined and average optical density score of positively stained cells was calculated.

Isolation, culture and identification of LFs. Pups were randomly selected for euthanasia and tissue collection on postnatal day 3, 7 or 14 . Under sterile conditions, lung tissue was removed, minced with fine seissors into $1 \mathrm{~mm}^{3}$ pieces and digested in $0.25 \%$ trypsin (Santa Cruz Biotechnology, Inc., Dallas, TX, USA) for $30 \mathrm{~min}$ at $37^{\circ} \mathrm{C}$ in a shaking water bath. The digested tissue was filtered through a sterile $53 \mathrm{~mm}$ cell strainer and pellet cells at $400 \mathrm{x}$ g for $5 \mathrm{~min}$ at $4^{\circ} \mathrm{C}$. The harvested cells were cultured with Dulbecco's modified Eagle's medium (DMEM; HyClone; GE Healthcare Life Sciences, Logan, UT, USA) supplemented with $10 \%$ fetal bovine serum (FBS; HyClone; GE Healthcare Life Sciences) and maintained at $37^{\circ} \mathrm{C}$ in a $5 \% \mathrm{CO}_{2}$-humidified incubator. $\mathrm{LFs}$ were used in subsequent experiments when confluent, elongated and spindle-shaped, and when they exhibited actiniform or paliform appearance.

Immunofluorescence and immunocytochemistry was used to detect LFs. Briefly, cultured LFs were fixed in $4 \%$ (w/v) paraformaldehyde for $30 \mathrm{~min}$ at $37^{\circ} \mathrm{C}$. Next, a primary antibody against vimentin (1:100; cat. no. sc-5565; Santa Cruz Biotechnology, Inc.) was added to the cells and incubated overnight at $4^{\circ} \mathrm{C}$, according to the manufacturer's protocol. Following primary incubation, cells were stained with fluorescein-isothiocyanate-conjugated goat anti-rat secondary antibody (1:100; cat. no. ZF-0312; OriGene Technologies, Inc.) for $90 \mathrm{~min}$ at $37^{\circ} \mathrm{C}$. LFs were stained using $50 \mu \mathrm{l}$ DAPI solution (1:100; cat. no. AR1176; Boster Biological Technology, Pleasanton, CA, USA) for $10 \mathrm{~min}$ at $37^{\circ} \mathrm{C}$ and a fluorescence microscope (magnification, $\mathrm{x} 400$ ) was used to analyze the results.

Immunocytochemical staining. The peroxidase-conjugated streptavidin method was performed to detect the expression levels of vimentin or p-ERK1/2 in LFs using an Histostain $^{\mathrm{TM}}$-Plus kit (OriGene Technologies, Inc.), according to the manufacturer's protocol. Briefly, LFs were fixed in cold $4 \%$ (w/v) paraformaldehyde for $30 \mathrm{~min}$ at $37^{\circ} \mathrm{C}$ and blocked for $15 \mathrm{~min}$ at room temperature with $10 \%$ goat serum. LFs were incubated with primary antibodies against vimentin (1:100; cat. no. sc-5565; Santa Cruz Biotechnology) or p-ERK (1:100; cat. no. 4370; Cell Signaling Technology, Inc.) overnight at $4^{\circ} \mathrm{C}$. Following primary incubation, LFs were incubated with biotinylated goat anti-rat secondary antibodies for $20 \mathrm{~min}$ at $37^{\circ} \mathrm{C}$ followed by HRP-labeled streptavidin for $20 \mathrm{~min}$ at $37^{\circ} \mathrm{C}$. LFs were subsequently stained with DAB solution (cat. no. ZLI-9031; OriGene Technologies, Inc.) for $1 \mathrm{~min}$ at room temperature and observed under a light microscope (magnification, $\mathrm{x} 400$ ). LFs were subjected to morphometric computerized image analysis using MetaMorph Software 
System (version IPP6.0; Universal Imaging, Inc., Bedford Hills, NY, USA), which was used to acquire images and quantify the average optical density score of positively stained cells.

Cell Counting kit (CCK)-8 colorimetric assay. LFs were cultured in 96-well plates $\left(5 \times 10^{5} /\right.$ well; $\left.100 \mu \mathrm{l}\right)$ in serum-free DMEM for $24 \mathrm{~h}$ at $37^{\circ} \mathrm{C}$. CCK-8 solution (cat. no. C0038; Beyotime Institute of Biotechnology, Haimen, China) was added to the wells $(10 \mu \mathrm{l} /$ well $)$ for $1 \mathrm{~h}$ at $37^{\circ} \mathrm{C}$. Absorbance was measured at $450 \mathrm{~nm}$ using an ELISA reader (UV-260; Shimadzu Corporation, Kyoto, Japan).

Flow cytometry cell cycle analysis. To assess cells in G0 phase of the cell cycle, LFs in logarithmic grow phase were collected and resuspended at density of $1 \times 10^{6}$ cells $/ \mathrm{ml}$. Following centrifugation at $400 \mathrm{x}$ g for $5 \mathrm{~min}$ at $4^{\circ} \mathrm{C}$, LFs were fixed in cold $75 \%$ ethanol overnight at $4^{\circ} \mathrm{C}$. Subsequently, LFs were treated with $50 \mu \mathrm{g} / \mathrm{ml}$ RNase (Sigma-Aldrich; Merck $\mathrm{KGaA}$, Darmstadt, Germany) for $30 \mathrm{~min}$ at $37^{\circ} \mathrm{C}$ and LFs were stained with $100 \mu \mathrm{g} / \mathrm{ml}$ propidium iodide (Sigma-Aldrich; Merck $\mathrm{KGaA}$ ) in the dark for $30 \mathrm{~min}$ at $4^{\circ} \mathrm{C}$. The cell cycle assay was performed using a BD FACSCalibur ${ }^{\mathrm{TM}}$ flow cytometer and CellQuest software (version 3.0; Becton Dickinson; BD Biosciences, Franklin Lakes, NJ, USA).

ELISA. Collagen type I (Col-I) secreted by LFs in logarithmic grow phase was determined by ELISA assay. Following centrifugation $(1,500 \mathrm{xg})$, cell culture supernatants were analyzed for Col-I expression using the mouse Col-I ELISA kit (cat. no. SEA571Mu; USCN Life Science Inc., Wuhan, China), according to the manufacturer's protocol. Absorption was measured at $450 \mathrm{~nm}$ using a microplate reader (ELX-800; BioTek Instruments, Inc., Winooski, VT, USA).

Reverse transcription-quantitative polymerase chain reaction $(R T$ - $q P C R)$. Quantitative changes in mRNA expression of genes encoding Col-I were assayed by RT-qPCR. Total RNA was extracted from LFs using TRIzol ${ }^{\circledR}$ reagent (Takara Biotechnology Co., Ltd., Dalian, China), according to the manufacturer's protocol. Total RNA (500 ng/ $\mu 1$ aliquots) were reverse-transcribed into cDNA using a PrimeScript RT Reagent kit (cat. no. DRR037S; Takara Biotechnology Co., Ltd.). qPCR was subsequently performed using the SYBR Premix Ex Taq ${ }^{\mathrm{TM}}$ (cat. no. DRR041S; Takara Biotechnology Co., Ltd.). The following gene-specific primers were designed and synthesized by Takara Biotechnology Co., Ltd. and used for the qPCR: Col-I forward, 5'-CTCCTGGCAAGAACGGA GATG-3' and reverse, 5'-CTGTTCCAGGCAATCCACGA-3'; $\beta$-actin forward, 5'-CCCGCGAGTACAACCTTCTT-3' and reverse, 5'-TCATCCATGGCGAACTGGTG-3'. The following thermocycling conditions were used for the qPCR: Initial denaturation at $95^{\circ} \mathrm{C}$ for $10 \mathrm{sec}, 40$ cycles of $95^{\circ} \mathrm{C}$ for $5 \mathrm{sec}$ and $60^{\circ} \mathrm{C}$ for $20 \mathrm{sec}$ using the LightCycle 2.0 real-time PCR System (Roche Diagnostics, Indianapolis, IN, USA). Relative quantification of gene expression was determined using the $2^{-\Delta \Delta \mathrm{Cq}}$ method (16).

Western blot analysis. Lung tissue and cultured LFs were washed three times with cold PBS and total protein was extracted using radioimmunoprecipitation assay buffer (cat. no. P0013; Beyotime Institute of Biotechnology). Total protein was quantified using a bicinchoninic acid assay kit (Sigma-Aldrich) and $50 \mu \mathrm{g}$ protein/lane was separated via SDS-PAGE on a $12 \%$ gel. Gels were run at $120 \mathrm{~V}$ for $2 \mathrm{~h}$ and separated proteins were transferred at $80 \mathrm{~V}$ for $2 \mathrm{~h}$ onto nitrocellulose membranes. Membranes were blocked for $1 \mathrm{~h}$ at $37^{\circ} \mathrm{C}$ for $1 \mathrm{~h}$ with $5 \%$ non-fat milk. The membranes were incubated with primary antibodies against p-ERK $(1 ; 1,000$; cat. no. 4370), ERK (1:1,000: cat. no. 4696) and $\beta$-actin (1:1,000; cat. no. 3700; all Cell Signaling Technology, Inc.) overnight at $4^{\circ} \mathrm{C}$. Following primary incubation, membranes were incubated with HRP-labeled goat anti-rat secondary antibody (1:2,000; cat. no. ZB2305; OriGene Technologies, Inc.) for $2 \mathrm{~h}$ at $37^{\circ} \mathrm{C}$. Membranes were washed three times in Tris-buffered saline containing $0.1 \%$ Tween $^{\circledR} 20$. Proteins bands were visualized using the Amersham ECL Advanced Western Blotting Detection kit (Amersham; GE Healthcare Life Sciences, Changhai, China). Images were collected using a ChemiDoc XRS system (Bio-Rad Laboratories, Inc., Hercules, CA, USA). Protein expression was quantified using Image-Pro Plus software (version 6.0; National Institutes of Health, Bethesda, MD, USA).

Statistical analysis. All experiments were repeated at least five times and data are presented as the mean \pm standard deviation. All statistical analyses were performed using SPSS software (version 17.0; SPSS, Inc., Chicago, IL, USA). Differences between the hyperoxia and normoxia control groups were assessed by one-way analysis of variance and a Student-Newman-Keuls test for multiple comparisons. $\mathrm{P}<0.05$ was considered to indicate a statistically significant difference.

\section{Results}

Exposure to hyperoxia leads to expanded alveoli and interstitial fibrosis in lung tissue. Pathological changes were evaluated by light microscopy in H\&E-stained sections of lung tissue from normoxia and hyperoxia-exposed rats (Fig. 1A). No marked differences in pathology were apparent at day 3 between hyperoxia-exposed and normoxia control lung tissues. Hyperoxia-associated differences were present on day 7 and increased towards day 14. Most notably were the expansion and dilatation of the alveoli, increased interstitial thickening and pulmonary interstitial fibrosis.

The alveolar developmental stage and the number of alveoli were determined by quantitative RAC. There were significantly fewer alveoli in the lung tissues of the hyperoxia group compared with the control group on day 7 and $14(\mathrm{P}<0.05$; Fig. 1B), suggesting the interruption of alveoli formation.

Lung fibrosis scores were significantly increased in the hyperoxia group at 7 and 14 day compared with the control group $(\mathrm{P}<0.01$; Fig. $1 \mathrm{C})$, suggesting that fibrosis started to develop between day 3 and 7 in hyperoxic rats. The results demonstrated that hyperoxia disrupted normal lung development and caused large, simplified alveolar structures and matrix fibrosis.

LF identification. In primary cultures $>95 \%$ of the cells were identified as LFs, with typical stellate morphology and an elongated spindle shape was observed under a light 
A

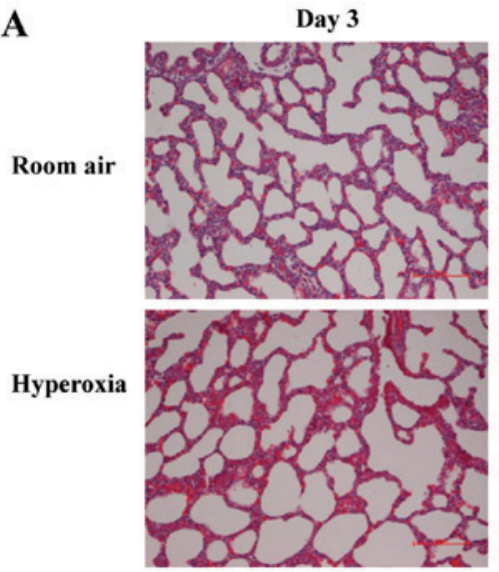

B

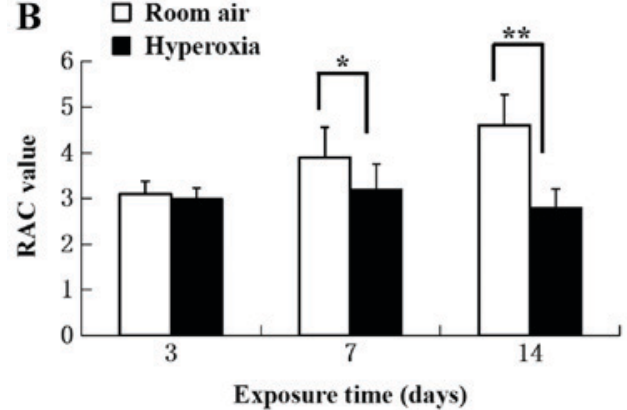

Day 7

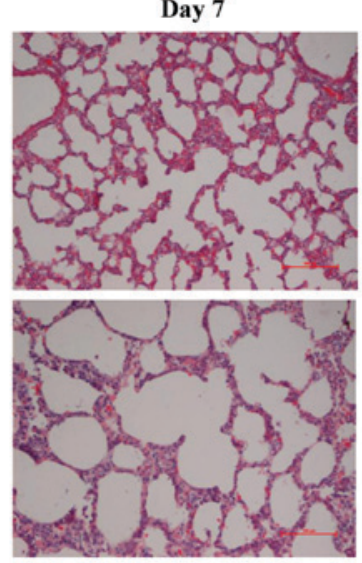

C
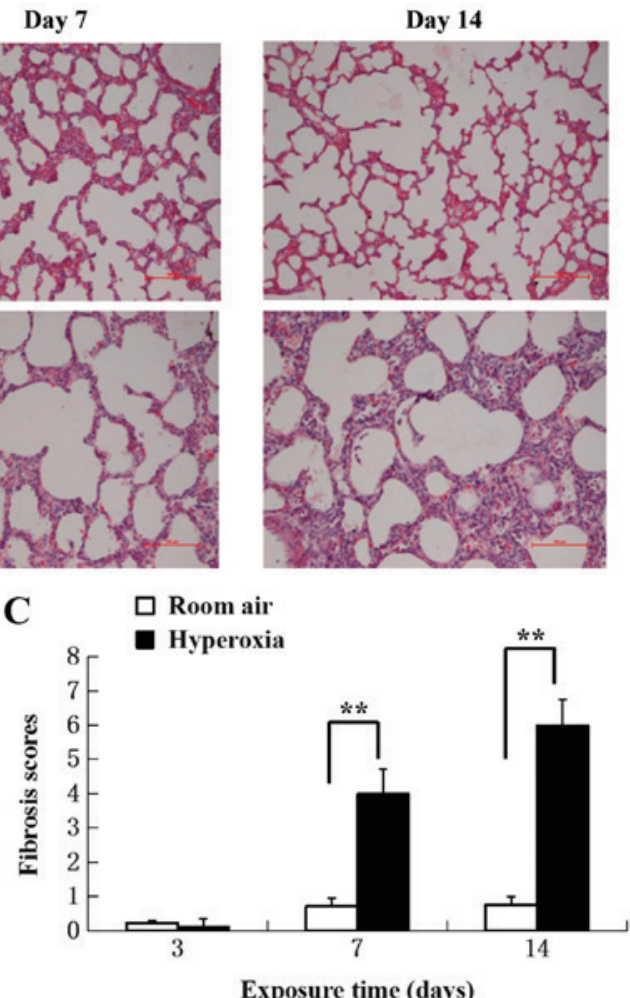

Figure 1. Lung morphology. (A) Hematoxylin and eosin staining of lung tissues at postnatal day 3, 7 and 14 . In the room air group, alveolar formation was gradually completed with lung development following birth. In the hyperoxia group, the following manifestations were observed over time: Decreased number of alveoli, dilation of terminal alveolar spaces, simplification of alveoli and pulmonary fibrosis. Scale bar, $100 \mu \mathrm{m}$. (B) RAC values were significantly lower in the hyperoxia group compared with the room air group starting from postnatal day 7 onwards ( $\mathrm{n}=5$ ). (C) Lung tissue fibrosis scores over time. Higher scores were determined in the hyperoxia group compared with the room air group starting at postnatal day 7 ( $\mathrm{n}=5$ ). ${ }^{*} \mathrm{P}<0.05,{ }^{* *} \mathrm{P}<0.01$. RAC, radial alveolar count.

microscope. In addition, positive cytoplasmic labeling using vimentin, a mesenchymal cell marker was also observed (Fig. 2A and B).

Exposure to hyperoxia induces proliferation of LFs. The effect of hyperoxia on proliferation of LFs was investigated by assaying cell cycle distribution by flow cytometry and CCK-8. On day 3, most of the LFs in hyperoxia $(78.85 \pm 1.49 \%)$ and control (80.14 $\pm 1.82 \%$ ) groups were in G0/G1 phase (Fig. 2C). On day 7, the proportion of cells in G0/G1 was decreased $(81.48 \pm 1.45$ vs. $88.43 \pm 1.98 \%$, respectively; $\mathrm{P}<0.01)$ whilst the proportion of cells in $\mathrm{S}$ phase was increased $(13.00 \pm 2.11$ vs. $9.71 \pm 1.24 \%$, respectively; $\mathrm{P}<0.05$ ) in $\mathrm{LFs}$ isolated from hyperoxia group rats compared with control rats. On day 14 , there was a greater difference in the proportion of cells in the $S$ phase LFs isolated from hyperoxia group rats compared with control rats (17.63 \pm 2.89 vs. $8.28 \pm 1.83 \%$, respectively; $\mathrm{P}<0.01)$. CCK- 8 assays revealed that hyperoxia significantly promoted cell proliferation when comparing day 7 with day $14(\mathrm{P}<0.01$; Fig. 2D). These results suggested that LF proliferation was associated with increasing proportions of cells entering the $\mathrm{S}$ phase.

Exposure to hyperoxia induces Col-I expression of LFs. Col-I protein was assayed in the supernatants of primary LF cultures to evaluate the effect of hyperoxia on fibrosis. ELISA assay revealed that hyperoxia resulted in the increased production of Col-I protein on day $7(\mathrm{P}<0.05)$ and $14(\mathrm{P}<0.01)$ compared with the room air control (Fig. 2E). RT-qPCR revealed that Col-I mRNA levels on day $3(\Delta \mathrm{Cq},-5.36 \pm 0.35)$ were significantly increased by 1.93 -fold compared with the control group $(\Delta \mathrm{Cq},-4.51 \pm 0.16 ; \mathrm{P}<0.01)$. On day 7, Col-I mRNA expression in the hyperoxia group $(\Delta \mathrm{Cq},-6.73 \pm 0.27)$ was significantly increased by 2.62 -fold compared with the control group $(\Delta \mathrm{Cq},-5.34 \pm 0.09 ; \mathrm{P}<0.01)$. Col-I mRNA levels in the hyperoxia group at day $14(\Delta \mathrm{Cq},-7.16 \pm 0.21)$ were significantly increased by 2.77 -fold compared with that in the room air control group $(\Delta \mathrm{Cq},-5.69 \pm 0.37 ; \mathrm{P}<0.01)$.

Hyperoxia induces time-dependent activation of ERK in lung tissue. Immunohistochemical assays of p-ERK protein levels demonstrated increased p-ERK1/2 antigen response in the cytoplasm and nuclei of pulmonary epithelial and mesenchymal cells in hyperoxic rats on day 7 and 14 compared with the room air control (Fig. 3A). The difference in expression in the two groups at day 3 was not significant ( $\mathrm{P}>0.05$; Fig. $3 \mathrm{~B}$ ). However, the protein levels of p-ERK detected significantly increased on day 7 in the hyperoxia group compared with the air control $(20.80 \pm 2.52$ vs. $8.32 \pm 0.88$, respectively; $\mathrm{P}<0.01$; Fig. 3B). Additionally, the protein levels of p-ERK detected significantly increased on day 14 in the hyperoxia group compared with the air control $(32.39 \pm 4.64$ vs. $9.24 \pm 0.54$, respectively; $\mathrm{P}<0.01$; Fig. 3B). Western blot analysis revealed that hyperoxia significantly increased ERK1/2 phosphorylation on day 7 and 14 compared with the room air control (Fig. 3C and D). 
A

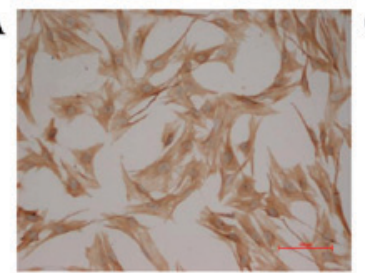

C

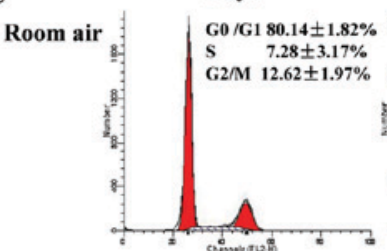

(10.8.
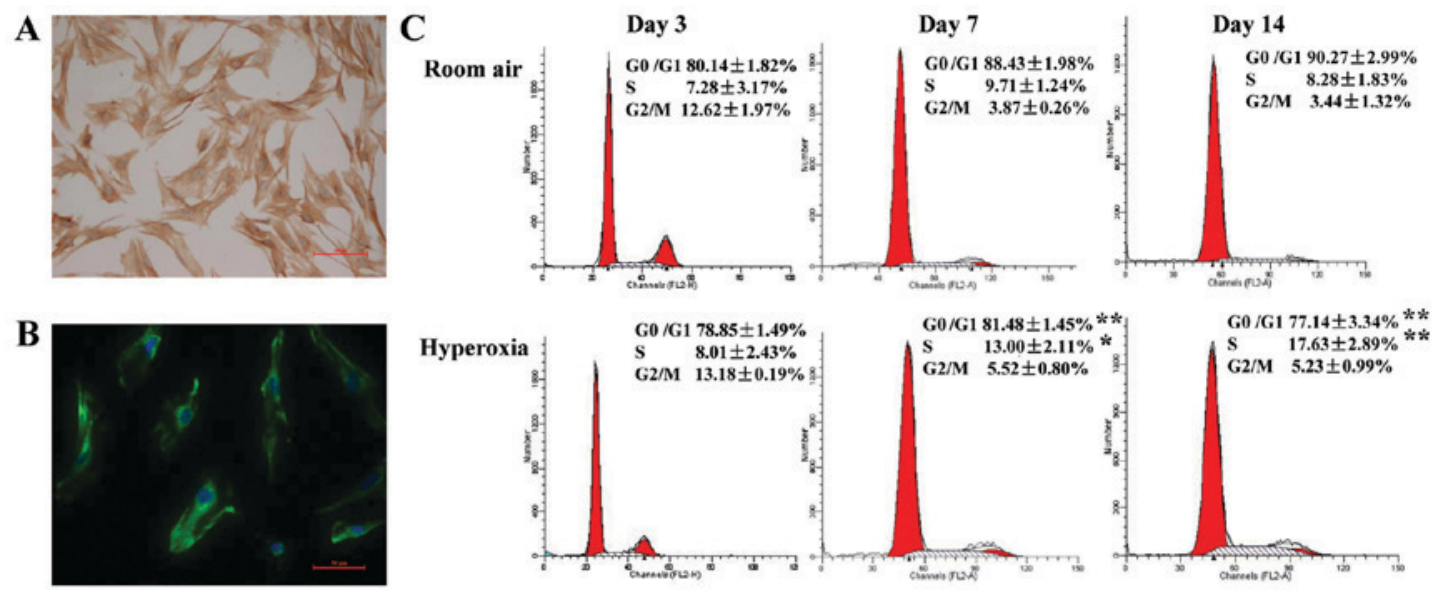

D
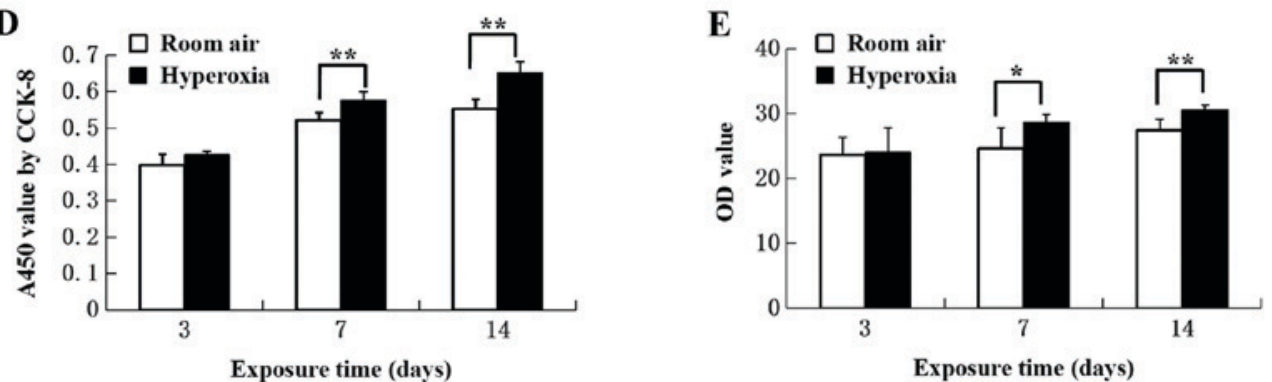

Figure 2. Identification of LFs and proliferation assays. (A) Immunocytochemical staining of LFs from control rats. Primary LFs were stained with vimentin. LFs exhibited stellate morphology, with an elongated spindle-like structure. Scale bar, $100 \mu \mathrm{m}$. (B) Immunofluorescence staining of LFs. Primary LFs from control rats were labeled with vimentin-specific antibodies (green) and cell nuclei were labeled with 4',6-diamidino-2-phenylindole (blue). Scale bar, $50 \mu \mathrm{m}$. (C) Cell-cycle distribution. Cell populations in G0/G1, S and G2/M phases were determined by calculating the mean of five independent experiments. The proportion of cells in the G0/G1 phase decreased, associated with an increase in the S phase in LFs from neonatal rats in the hyperoxia group at postnatal day 7 and 14 compared with the room air control group (n=5). (D) Effect of hyperoxia on cell proliferation. CCK-8 assays were used to measure proliferation. Hyperoxia promoted cell proliferation at postnatal day 7 and $14(n=6)$. (E) Col-I secreted protein levels in LFs determined by ELISA. An increase was observed in the hyperoxia group compared with the room air control group $(\mathrm{n}=5) .{ }^{*} \mathrm{P}<0.05,{ }^{* *} \mathrm{P}<0.01$. LF, lung fibroblast; Col-I, collagen type I; CCK-8, cell counting kit-8; OD, optical density.
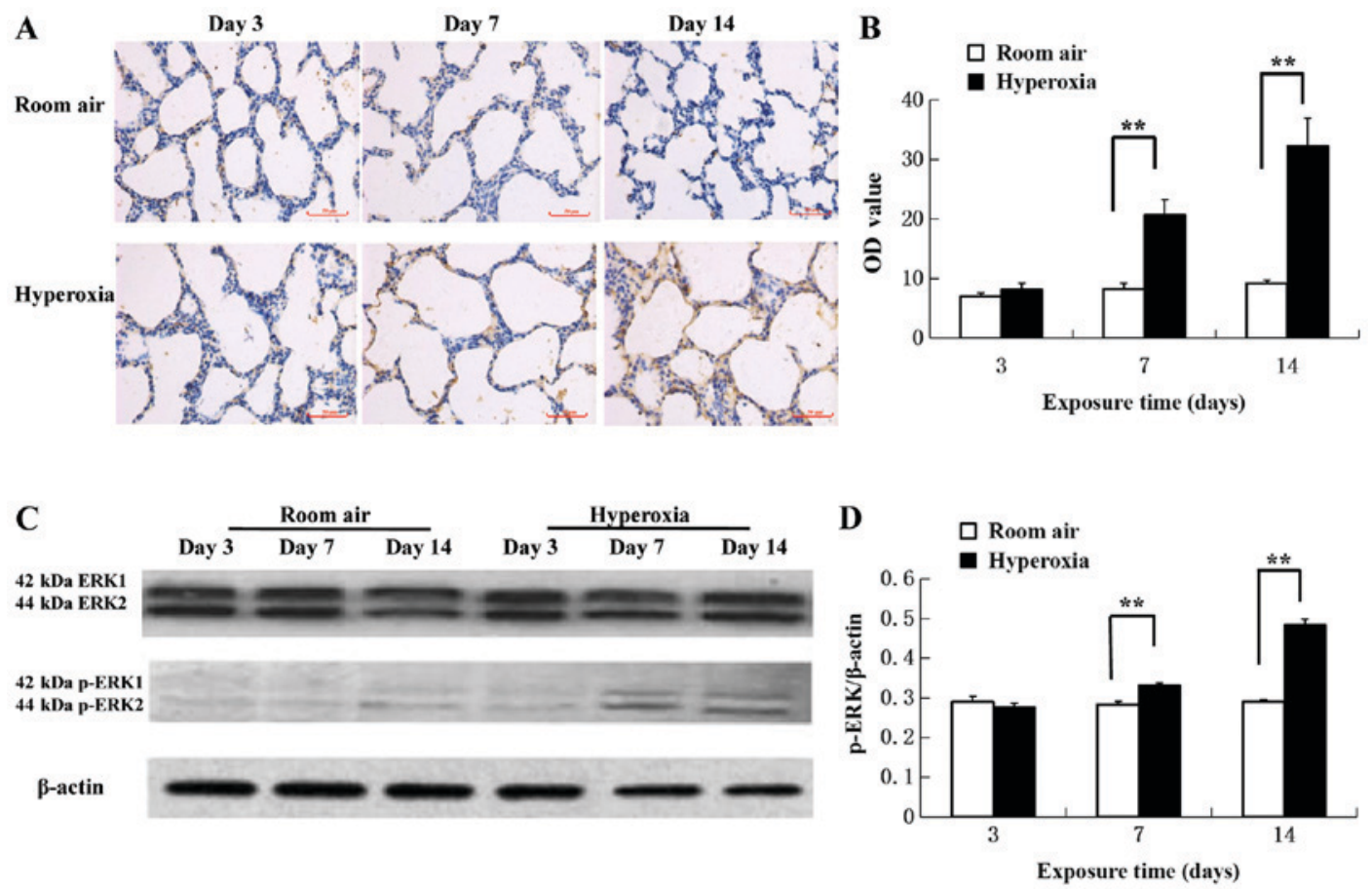

Figure 3. Phosphorylation of ERK1/2 in lung tissue samples. (A) Increased p-ERK1/2 antigen levels were observed in the cytoplasm and nucleus of pulmonary epithelial and mesenchymal cells by immunohistochemistry using the peroxidase-conjugated streptavidin method. Scale bar, $50 \mu \mathrm{m}$. (B) Protein levels of p-ERK were detected by immunohistochemistry. p-ERK levels increased in the hyperoxia group starting from postnatal day 7 compared with the room air control group $(\mathrm{n}=5)$. (C) Western blot analysis of lung tissue samples detecting p-ERK1/2, ERK1/2 and $\beta$-actin. (D) Western blot quantification suggested that the intergroup difference was more significant at postnatal day 7 and 14 for $\mathrm{p}$-ERK levels $(\mathrm{n}=5) .{ }^{* *} \mathrm{P}<0.01$. ERK, extracellular signal-regulated kinase; $\mathrm{p}$, phosphorylation. 
$\mathbf{A}$
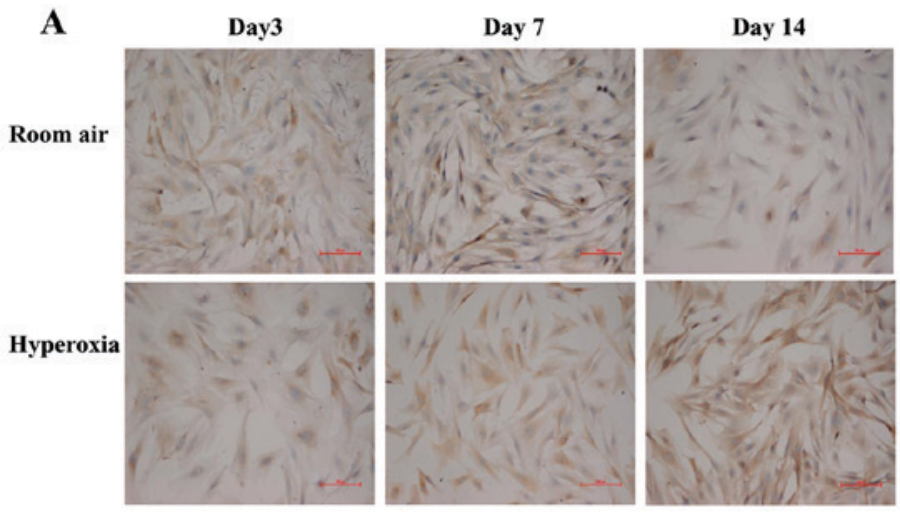

C

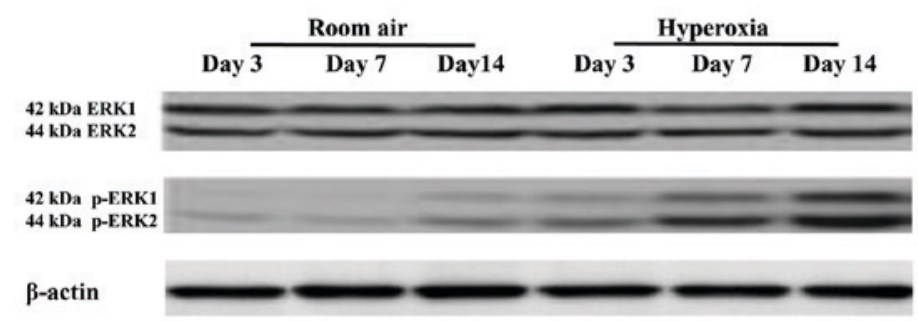

B

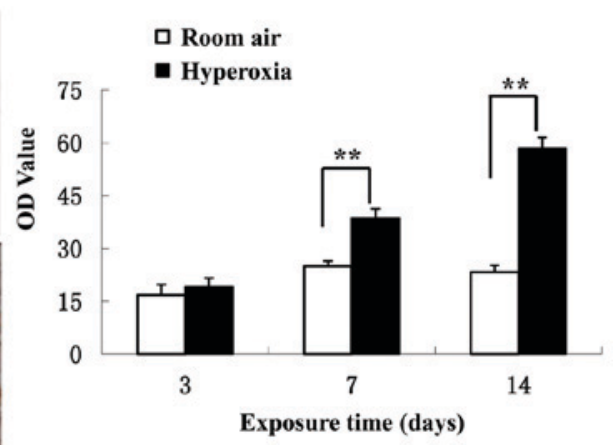

D

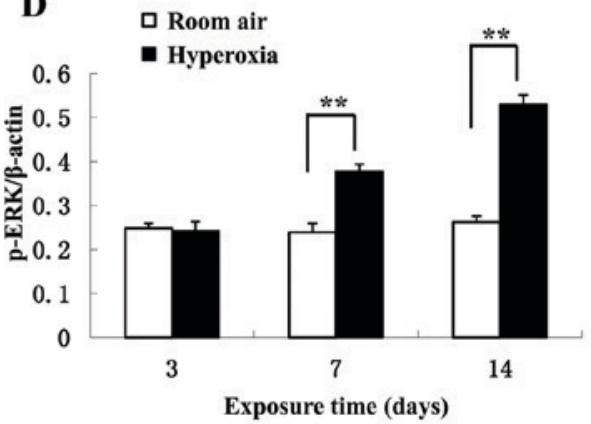

Figure 4. Phosphorylation of ERK1/2 in LFs. (A) Immunocytochemistry was performed in LFs to detect were the expression levels of p-ERK1/2. Increased p-ERK1/2 levels were detected in the cell cytoplasm and nucleus in the hyperoxia groups at postnatal day 7 and 14 . Scale bar, $50 \mu \mathrm{m}$. (B) p-ERK levels were detected by immunohistochemistry. p-ERK levels increased in the hyperoxia group starting from postnatal day 7 compared with the room air control group $(n=5)$. (C) Western blot analysis of the LFs detecting p-ERK1/2, ERK1/2 and $\beta$-actin. (D) Quantification of western blots. Following hyperoxic exposure levels of phosphorylated ERK1/2 increased on day 7 and 14 compared with the room air control $(\mathrm{n}=5) .{ }^{* *} \mathrm{P}<0.01$. ERK, extracellular signal-regulated kinase; p, phosphorylation; LF, lung fibroblast.

Immunocytochemical staining of LFs from primary cultures demonstrated that p-ERK levels are increased in the cytoplasm in the hyperoxia group compared with the control group (Fig. 4A). On day 3, there was no significant difference in p-ERK levels between the hyperoxic and control groups ( $\mathrm{P}>0.05$; Fig. 4B). However, the p-ERK levels significantly increased on day 7 in the hyperoxia group compared with the control group (38.64 \pm 2.68 vs. $24.93 \pm 1.51$, respectively; $\mathrm{P}<0.01)$. Additionally, the $\mathrm{p}-\mathrm{ERK}$ levels significantly increased on on day 14 in the hyperoxia group compared with the control group $(58.53 \pm 2.97$ vs. $23.33 \pm 1.90$, respectively; $\mathrm{P}<0.01)$. Western blot analysis revealed that hyperoxia significantly increased ERK1/2 phosphorylation on day 7 and 14 compared with the room air control ( $\mathrm{P}<0.01$; Fig. $4 \mathrm{C}$ and $\mathrm{D})$ confirming the immunocytochemistry results. There was no change in the total expression of ERK1/2 in lung tissues and primary cultured LFs (data not shown).

\section{Discussion}

BPD is a chronic lung disease commonly seen in premature infants and the associated morbidity has increased with the use of pulmonary surfactants, assisted ventilation and oxygen treatment $(4,17)$. BPD is a consequence of long-term oxygen therapy threatening the health and life of premature infants (18). The pathology of the pulmonary response to hyperoxia is characterized by remodeling of the airway development and parenchymal, and the vascular structure. This situation is further influenced by the immaturity of specific lung cells in newborn rats that develop BPD $(19,20)$. LFs are present in the ECM and serve essential roles during pulmonary epithelial injury and in response to the fibrosis development in BPD. It has been observed that in vitro the direct effect of hyperoxia on LFs over $48 \mathrm{~h}$ inhibited proliferation and decreased collagen expression (21). A previous study demonstrated that hyperoxia on lung fibroblasts for $48 \mathrm{~h}$ in vitro led to the inhibition of cellular proliferation and decreased collagen expression (6). The direct effect of LFs to hyperoxic exposure was contradictory to the pathological interstitial proliferation character of BPD (22). Primary cultured LFs from newborn rats with BPD are a promising technique to investigate mechanisms of hyperoxia-induced fibrosis. In the current study, hyperoxia disrupted the normal lung development by exhibiting large, simplified alveoli and pulmonary fibrosis. Primary cultured LFs from hyperoxic rats demonstrated a proliferative status with increased levels of Col-I secretion. Hyperoxia upregulated the phosphorylation of ERK1/2 in lung tissues and LFs from rats on postnatal day 7 and 14 . These findings indicated that hyperoxia promoted an increase of proliferation of LFs in newborn rats linearly over time and the phosphorylation of ERK1/2 may have served a role in this process.

The regulation of LF proliferation via the ERK signaling pathway was in line with the pathologic changes observed in BPD. Hyperoxic exposure has been demonstrated to lead to myofibroblast accumulation, patchy areas of interstitial thickening and increased lung Col-I and $\alpha$-smooth muscle 
actin (SMA) levels (23-26). The findings of the current study suggested that the ERK signaling pathway may serve an important role in regulating primary cultured LF proliferation and is in accordance with previous studies (27-30). Exposure of newborn Sprague-Dawley rat pups, started within $12 \mathrm{~h}$ of birth, for 1 week with $95 \%$ oxygen followed by two weeks with $60 \%$ oxygen resulted in an increase of total collagen, Col-I and $\alpha$-SMA expression and activated ERK in lung tissues on postnatal day 7 and 21, consistent with the development of pulmonary fibrosis (27). Hyperoxia has further been reported to promote alveolar interstitial fibroblast-to-myofibroblast transdifferentiation (28). Increased p-ERK1/2, $\alpha$-SMA and Col-I expression was further promoted in human fetal LFs exposed to $95 \%$ oxygen for $48 \mathrm{~h}$ (29). Following bleomycin administration to produce acute lung injury in rats, high tidal volume ventilation induced lung fibrosis that was partly dependent on the ERK1/2 signaling pathway activation and was attenuated by PD98059, an ERK1/2 inhibitor (30).

The ERK signaling pathway may be important in BPD due to its participation in normal lung development. However, further research is required to validate these finding. The Mek gene encodes ERKs and loss of the Mekl gene in rats resulted in placental defects and embryonic death (31). Mek2-mutant rats did not express an abnormal phenotype as a result of a protein threshold effect (13). Inactivation of both Mek genes in epithelial cells causes lung agenesis and may be fatal, and mutant Mek genes in mesenchymal cells present as lung hypoplasia, tracheal defects and neonatal death, but not kyphosis and omphalocele (31). Expression studies have indicated potential interactions of the ERK and Wnt signaling pathways during lung development (32). Dermol ${ }^{\text {Cre }}$-deletion rats are deficient in the mesenchyme-specific Mek gene function, which is associated with intrauterine growth restriction, giant omphalocele, kyphosis, lung hypoplasia, altered trachea patterning and still birth (33). Lung hypoplasia is accompanied by reduced branching, decreased mesenchymal cell proliferation and increased apoptosis (6).

ERK also appears to promote fibrosis through transduction signals that involve matrix metalloproteinases (MMPs) and transforming growth factor (TGF) $\beta$ (34-38). MS80 is a novel, sulfated oligosaccharide extracted from seaweed and it inhibits bleomycin-induced pulmonary fibrosis in rats by arresting TGF- $\beta 1$-induced proliferation of human embryonic LFs, collagen deposition and MMP activity (34). TGF- $\beta 1$ has also been suggested to induce $\alpha$-SMA expression and collagen production in human LFs via ERK1/2 activation (35), and MMP mRNA and p-ERK1/2 expression increased following TGF- $\beta$ stimulation in primary cultured human LFs (36). Collectively, the evidence indicates that the promotion of fibrosis by MMPs and TGF- $\beta$ is closely associated with the function of ERK1/2. However, there is no direct evidence to suggest whether ERK1/2 is an up- or downstream regulator of TGF- $\beta$ or MMPs. Previous studies have demonstrated that hydrogen sulfide and rosiglitazone suppress migration, proliferation and phenotypic differentiation of human LFs in vitro through inhibition of ERK activation and that these compounds may be effective in treating pulmonary interstitial fibrosis $(37,38)$. ERK1/2 may become a target of measures to prevent and treat pulmonary hypoplasia and fibrosis associated with BPD in premature infants.

\section{Acknowledgements}

The authors would like to thank Dr Xueyan Liu (Shengjing Hospital of China Medical University) for her encouragement and support of this study.

\section{Funding}

This work was funded by the Natural Science Foundation of China (grant no. 30801245).

\section{Availability of data and materials}

All datasets used and/or analyzed during the current study are available from the corresponding author on reasonable request.

\section{Authors' contributions}

YH performed the experiments. JF collected and analyzed the data. XX designed the study and was the major contributor in writing the manuscript. All authors read and approved the final manuscript.

\section{Ethics approval and consent to participate}

The current study was approved by the Medical Ethics Committee at Shengjing Hospital of China Medical University (no. 2018PS209K).

\section{Patient consent for publication}

Not applicable.

\section{Competing interests}

The authors declare that they have no competing interests.

\section{References}

1. Kayton A, Timoney P, Vargo L and Perez JA: A review of oxygen physiology and appropriate management of oxygen levels in premature neonates. Adv Neonatal Care 18: 98-104, 2018.

2. Vogel ER, Britt RD Jr, Trinidad MC, Faksh A, Martin RJ, MacFarlane PM, Pabelick CM and Prakash YS: Perinatal oxygen in the developing lung. Can J Physiol Pharmacol 93: 119-127, 2015.

3. Perrone S, Bracciali C, Di Virgilio N and Buonocore G: Oxygen use in neonatal care: A two-edged sword. Front Pediatr 9: 143, 2017.

4. Jobe AH: Mechanisms of lung injury and bronchopulmonary dysplasia. Am J Perinatol 33: 1076-1078, 2016.

5. Kalikkot Thekkeveedu R, Guaman MC and Shivanna B: Bronchopulmonary dysplasia: A review of pathogenesis and pathophysiology. Respir Med 132: 170-177, 2017.

6. Coalson JJ: Pathology of bronchopulmonary dysplasia. Semin Perinatol 30: 179-184, 2006.

7. Sheppard D: Epithelial-mesenchymal interactions in fibrosis and repair. Transforming growth factor- $\beta$ activation by epithelial cells and fibroblasts. Ann Am Thorac Soc 1 (Suppl 12): S21-S23, 2015.

8. McGowan S: Understanding the developmental pathways pulmonary fibroblasts may follow during alveolar regeneration. Cell Tissue Res 367: 707-719, 2017.

9. Murray MJ: The role of netrins and their receptors in epithelial mesenchymal plasticity during development. Cells Tissues Organs 203: 71-81, 2017. 
10. Hayes D Jr, Feola DJ, Murphy BS, Shook LA and Ballard HO: Pathogenesis of bronchopulmonary dysplasia. Respiration 79: 425-436, 2010.

11. Porzionato A, Sfriso MM, Mazzatenta A, Macchi V, De Caro R and Di Giulio C: Effects of hyperoxic exposure on signal transduction pathways in the lung. Respir Physiol Neurobiol 209: $106-114,2015$.

12. Rubinfeld $\mathrm{H}$ and Seger R: The ERK cascade: A prototype of MAPK signaling. Mol Biotechnol 31: 151-174, 2005.

13. Bélanger LF, Roy S, Tremblay M, Brott B, Steff AM, Mourad W, Hugo P, Erikson R and Charron J: Mek2 is dispensable for mouse growth and development. Mol Cell Biol 23: 4778-4787, 2003.

14. Jakkula M, Le Cras TD, Gebb S, Hirth KP, Tuder RM, Voelkel NF and Abman SH: Inhibition of angiogenesis decreases alveolarization in the developing rat lung. Am J Physiol Lung Cell Mol Physiol 279: L600-L607, 2000.

15. Ashcroft T, Simpson JM and Timbrell V: Simple method of estimating severity of pulmonary fibrosis on a numerical scale. J Clin Pathol 41: 467-470, 1988.

16. Livak KJ and Schmittgen TD: Analysis of relative gene expression data using real-time quantitative PCR and the 2(-Delta Delta C (T)) method. Methods 25: 402-408, 2001.

17. Coalson JJ: Experimental models of bronchopulmonary dysplasia. Biol Neonate 1 (Suppl 71): S35-S38, 1997.

18. Baraldi E and Filippone M: Chronic lung disease after premature birth. N Engl J Med 357: 1946-1955, 2007.

19. Chen Y, Whitney PL and Frank L: Comparative responses of premature versus full-term newborn rats to prolonged hyperoxia. Pediatr Res 35: 233-237, 1994.

20. Cox AM, Gao Y,Perl AT, Tepper RS and Ahlfeld SK: Cumulative effects of neonatal hyperoxia on murine alveolar structure and function. Pediatr Pulmonol 52: 616-624, 2017.

21. Hussain N, Wu F, Christian C and Kresch MJ: Hyperoxia inhibits fetal rat lung fibroblast proliferation and expression of procollagens. Am J Physiol 273: L726-L732, 1997.

22. Silva DM, Nardiello C, Pozarska A and Morty RE: Recent advances in the mechanisms of lung alveolarization and the pathogenesis of bronchopulmonary dysplasia. Am J Physiol Lung Cell Mol Physiol 309: L1239-L1272, 2015.

23. Porzionato A, Zaramella P, Macchi V, Grisafi D, Salmaso R, Baraldi M, Fornaro E, Tassone E, Masola V, Onisto M, et al: Fluoxetine may worsen hyperoxia-induced lung damage in neonatal rats. Histol Histopathol 27: 1599-1610, 2012

24. Porzionato A, Zaramella P, Macchi V, Sarasin G, Di Giulio C, Rigon A, Grisafi D, Dedja A, Chiandetti L and De Caro R: Cyclosporine and hyperoxia-induced lung damage in neonatal rats. Respir Physiol Neurobiol 187: 41-46, 2013.

25. Grisafi D, Pozzobon M, Dedja A, Vanzo V, Tomanin R, Porzionato A, Macchi V, Salmaso R, Scarpa M, Cozzi E, et al: Human amniotic fluid stem cells protect rat lungs exposed to moderate hyperoxia. Pediatr Pulmonol 48: 1070-1080, 2013.

26. Grisafi D, Tassone E, Dedja A, Oselladore B, Masola V, Guzzardo V, Porzionato A, Salmaso R, Albertin G, Artusi C, et al: L-citrulline prevents alveolar and vascular derangement in a rat model of moderate hyperoxia-induced lung injury. Lung 190 419-430, 2012.
27. Jiang JS, Lang YD, Chou HC, Shih CM, Wu MY, Chen CM and Wang LF: Activation of the renin-angiotensin system in hyperoxia-induced lung fibrosis in neonatal rats. Neonatology 101: 47-54, 2012

28. Li Z, Choo-Wing R, Sun H, Sureshbabu A, Sakurai R, Rehan VK and Bhandari V: A potential role of the JNK pathway in hyperoxia-induced cell death, myofibroblast transdifferentiation and TGF- $31-$ mediated injury in the developing murine lung. BMC Cell Biol 12: 54, 2011.

29. Lang YD, Hung CL, Wu TY, Wang LF and Chen CM: The renin-angiotensin system mediates hyperoxia-induced collagen production in human lung fibroblasts. Free Radic Biol Med 49: 88-95, 2010.

30. Li LF, Liao SK, Huang CC, Hung MJ and Quinn DA: Serine/threonine kinase-protein kinase B and extracellar signal-regulated kinase regulate ventilator-induced pulmonary fibrosis after bleomycin-induced acute lung injury: A prospective, controlled animal experiment. Crit Care 12: R103, 2008

31. Aoidi R, Maltais A and Charron J: Functional redundancy of the kinases MEK1 and MEK2: Rescue of the Mek1 mutant phenotype by Mek 2 knock-in reveals a protein threshold effect. Sci Signal 9: ra9, 2016

32. Boucherat O, Landry-Truchon K, Aoidi R, Houde N, Nadeau V, Charron J and Jeannotte L: Lung development requires an active ERK/MAPK pathway in the lung mesenchyme. Dev Dyn 246: 72-82, 2017.

33. Boucherat O, Nadeau V, Bérubé-Simard FA, Charron J and Jeannotte L: Crucial requirement of ERK/MAPK signaling in respiratory tract development. Development 142: 3801, 2015.

34. Jiang HD and Guan HS: MS80, a novel sulfated oligosaccharide, inhibites pulmonary fibrosis by targeting TGF-betal both in vitro and in vivo. Acta Pharmacol Sin 30: 973-979, 2009.

35. Caraci F, Gili E, Calafiore M, Failla M, La Rosa C, Crimi N, Sortino MA, Nicoletti F, Copani A and Vancheri C: TGF-beta1 targets the GSK-3beta/beta-catenin pathway via ERK activation in the transition of human lung fibroblasts into myofibroblasts. Pharmacol Res 57: 274-282, 2008.

36. Asano K, Shikama Y, Shoji N, Hirano K, Suzaki H and Nakajima H: Tiotropium bromide inhibits TGF- $\beta$-induced MMP production from lung fibroblasts by interfering with Smad and MAPK pathways in vitro. Int J Chron Obstruct Pulmon Dis 5: 277-286, 2010.

37. Fang LP, Lin Q, Tang CS and Liu XM: Hydrogen sulfide suppresses migration, proliferation and myofibroblast transdifferentiation of human lung fibroblasts. Pulm Pharmacol Ther 22: 554-561, 2009.

38. Lin Q, Fang LP, Zhou WW and Liu XM: Rosiglitazone inhibits migration, proliferation, and phenotypic differentiation in cultured human lung fibroblasts. Exp Lung Res 36: 120-128, 2010.

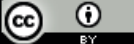

This work is licensed under a Creative Commons Attribution 4.0 International (CC BY 4.0) License. 